\title{
Determination of Fluorine Chemical Structure in Slag by Thermal Hydrolysis He-MIP-OES
}

\author{
Michihiro AImoto, ${ }^{* 1 \dagger}$ Shun-ichi HaYaShI, ${ }^{* 1}$ Kazuko Yamamoto, ${ }^{* 2}$ Masaki OHATA, ${ }^{* 3}$ and \\ Yukio ОКАмото $* 4$ \\ *1 Advanced Technology Research Laboratories, Nippon Steel and Sumitomo Metal Corp., Futtsu, Chiba 293-8511, \\ Japan \\ *2 Hitachi High-Tech Science Corp., Hitachinaka, Ibaraki 312-0033, Japan \\ *3 National Metrology Institute of Japan, National Institute of Advanced Industrial Science and Technology, \\ Tsukuba, Ibaraki 305-8567, Japan \\ *4 Research Institute of Industrial Technology, Toyo University, Kawagoe, Saitama 350-8585, Japan
}

\begin{abstract}
A novel microwave-induced helium plasma optical emission spectrometry (He-MIP-OES) combined with a thermal hydrolysis sample introduction system was newly established for the determination of fluorine (F) compounds in slags. The MIP maintained through an Okamoto cavity was adopted, which was quite stable and provided a higher detection capability of $\mathrm{F}$ by helium plasma. The basic analytical performance of He-MIP-OES combined with an ultrasonic nebulizer for $\mathrm{F}$ analysis was also examined, and expected results could be obtained. The thermal hydrolysis behavior of $\mathrm{CaF}_{2}, \mathrm{Ca}_{4}\left(\mathrm{Si}_{2} \mathrm{O}_{7}\right)(\mathrm{F}, \mathrm{OH})_{2}$ and $\mathrm{Ca}_{5}\left(\mathrm{PO}_{4}\right)_{3} \mathrm{~F}$, as known $\mathrm{F}$ chemical structures in slag, was also examined by thermal hydrolysis He-MIP-OES; F compounds in actual slag could be successfully identified and determined by this developed system.
\end{abstract}

Keywords Microwave induced He plasma (He-MIP), Okamoto cavity, optical emission spectrometry, thermal hydrolysis, fluorine compounds, slag

(Received February 15, 2018; Accepted April 11, 2018; Published June 10, 2018)

\section{Introduction}

Slags are by-products of metals refining processes and incinerators. They are effectively used in various ways, such as roadbeds, civil engineering works and fertilizers. It is very important to ensure the safe utilization of slag to protect the environment. The fluorine $(\mathrm{F})$ is an environmentally hazardous substance, and legal regulations are provided throughout the world. When utilizing slag, it can be thought that the amount of F elution from slag depends on the kinds and concentrations of coexistent ions and $\mathrm{pH}$ in water as well as the solubility of various kinds of compounds, including $\mathrm{F}$ contained in slag. In order to minimize the elution of $\mathrm{F}$ from slag to the environment, it is very important to investigate and control the contents of $F$ compounds in slag. ${ }^{1,2}$

Various analytical methods have been studied to identify $\mathrm{F}$ compounds. Surface analysis methods, for example X-ray photoelectron spectroscopy (XPS), scanning electron microscope (SEM) and electron probe micro analyzer (EPMA), ${ }^{3-6}$ were known to be effective tools for analyzing F; however, specific chemical information concerning slag could not be obtained. Solid-state nuclear magnetic resonance (NMR) with a ${ }^{19} \mathrm{~F}$ and ${ }^{31} \mathrm{P}$ cross polarization/magic angle spinning $\left({ }^{19} \mathrm{~F}\left\{{ }^{31} \mathrm{P}\right\} \mathrm{CP} / \mathrm{MAS}\right)$ $\operatorname{method}^{7}$ can also be applied to analyze the chemical state of F;

$\dagger$ To whom correspondence should be addressed.

E-mail: aimoto.d7k.michihiro@jp.nssmc.com however, this is difficult since actual slag contains iron $(\mathrm{Fe})$ compounds.

The melting points of fluorite $\left(\mathrm{CaF}_{2}\right)$, fluorapatite $\left(\mathrm{Ca}_{5}\left(\mathrm{PO}_{4}\right)_{3} \mathrm{~F}\right)$ and cuspidine $\left(\mathrm{Ca}_{4}\left(\mathrm{Si}_{2} \mathrm{O}_{7}\right)(\mathrm{F}, \mathrm{OH})_{2}\right)$, which might be present in slag, were at quite high temperatures, and were reported as $1402^{\circ} \mathrm{C},{ }^{8} 1644^{\circ} \mathrm{C}^{9}$ and $1407^{\circ} \mathrm{C},{ }^{10}$ respectively. However, pyrohydrolysis separation combined with ion chromatography, ${ }^{11}$ is one of the analytical methods for thermally decomposing all F compounds in slag by elevating the temperature up to $1100^{\circ} \mathrm{C}$ in the presence of water, and comparable to the conventional method of sample decomposition-distillation separationlanthanum/alizarin complexone spectrometry. In this case, it is assumed that $\mathrm{F}$ in the $\mathrm{F}$ compounds reacts with $\mathrm{H}_{2} \mathrm{O}$ to become $\mathrm{HF}$, as shown in the reaction (1).

$$
n \mathrm{MF}_{2}+n \mathrm{H}_{2} \mathrm{O} \longrightarrow \mathrm{MO}_{\mathrm{n}}+2 n \mathrm{HF} \uparrow
$$

However, the temperatures of thermal hydrolysis of each $F$ compound were unknown because there was no technique for continuously detecting $\mathrm{F}$ when pyrohydrolyzing. Empirically, once the temperature was raised to $1100^{\circ} \mathrm{C}$, all $\mathrm{F}$ compounds were known to be decomposed hydrothermally.

A helium microwave-induced plasma optical emission spectrometry (He-MIP-OES) was expected to be an effective analytical method for $\mathrm{F}$ compounds, since the plasma gas of $\mathrm{He}$ revealed a higher ionization potential than that of F. ${ }^{12-15}$ From this point of view, we adopted He-MIP-OES and applied an Okamoto-cavity ${ }^{15,16}$ to sustain He-MIP as an excitation source 
for $\mathrm{F}$ compounds. The Okamoto-cavity produces an annular flame-like plasma in which the electric field of the microwaves is concentrated at the surrounding portion of the plasma, resulting in a doughnut-like structure; therefore, a sample mist or gas can be easily introduced into a central channel of the plasma, as similar to ICP. The Okamoto cavity can provide various quite stable plasmas, such as $\mathrm{N}_{2}, \mathrm{O}_{2}$, Air, $\mathrm{Ar}$ and $\mathrm{He}$ plasma, ${ }^{14,17}$ and has been variously used as a new plasma source for spectrometry, ${ }^{18-26}$ including $\mathrm{F}$ analysis. ${ }^{13-15}$

In this study we examined the hydrolytic decomposition of $\mathrm{F}$ compounds up to $1000^{\circ} \mathrm{C}$ by analyzing $\mathrm{F}$ continuously using He-MIP-OES. If the decomposition temperatures are different among $\mathrm{F}$ compounds, it is considered that mineral identification can be possible. However, it was unknown whether the $\mathrm{F}$ compounds showed a clear thermal hydrolysis behavior. Moreover, the reason why we applied He-MIP-OES was its expectation of a higher detection capability on $\mathrm{F}$ and the ability to conduct continuous and real-time analysis since decomposed gaseous $\mathrm{F}$ in the carrier gas could be directly introduced into the He-MIP and analyzed. Thus we could elucidate the sensitivity of He-MIP-OES if it was enough with respect to $\mathrm{F}$ detection in decomposed gas.

\section{Experimental}

\section{Reagents and specimens}

For the F standard solution, sodium fluoride (NaF, Wako Special Grade, Wako Pure Chemical Industries, Ltd.) was diluted by pure water. For $\mathrm{F}$ compounds, fluorite $\left(\mathrm{CaF}_{2}\right.$, Wako Special Grade, Wako Pure Chemical Industries, Ltd.) was used. For synthesizing cuspidine $\left(\mathrm{Ca}_{4}\left(\mathrm{Si}_{2} \mathrm{O}_{7}\right)(\mathrm{F}, \mathrm{OH})_{2}\right), \quad \mathrm{SiO}_{2}$ (Guaranteed Reagent, Wako Pure Chemical Industries, Ltd.) and $\mathrm{CaF}_{2}$ were mixed as molar equivalents and heated by an electric furnace in an argon (Ar) atmosphere with a closed crucible so as to avoid the volatilization of $\mathrm{F}$. In order to synthesize fluoroapatite $\left(\mathrm{Ca}_{5}\left(\mathrm{PO}_{4}\right)_{3} \mathrm{~F}\right), \quad 10 \mathrm{CaO} \cdot 3 \mathrm{P}_{2} \mathrm{O}_{5} \cdot \mathrm{H}_{2} \mathrm{O}$ (Wako Pure Chemical Industries, Ltd.) and $\mathrm{CaF}_{2}$ reagents were treated under the same conditions of synthesizing cuspidine. The fluorite and the synthesized cuspidine and fluoroapatite were grounded and sieved under $75 \mu \mathrm{m}$ in particle diameter; then, same particle size as much as possible to the artificial slag specimens shown in Table 1, expressed in terms of oxide, except for the fluorine concentration, were used in this study. The contents of the elements in slags, except F, were determined by XRF. The total fluorine concentration was determined by lanthanum/alizarin complexone spectrometry after the distillation of $\mathrm{F}$ from an alkaline-fused and acid-decomposed samples solution.

\section{Apparatus}

Figure 1 shows the instrumental setup of thermal hydrolysis He-MIP-OES. The MIP-OES system, equipped with an Okamoto-cavity, was custom-built by Hitachi High-technology corporation (Hitachi, Ibaraki, Japan). The maximum output and microwave frequency of the power supply unit (Nihon Koshuha Co., Ltd.) were $1.5 \mathrm{~kW}$ and $2.45 \mathrm{GHz}$, respectively, with a shield mechanism against any external leakage of microwaves. He gas (purity: 99.995\%) was used as the plasma and carrier gas. The spectrometer was of the sequential type with Czerny-Turner mounting, $650 \mathrm{~mm}$ in focal length with the $25 \mu \mathrm{m}$ width of input/output curved slits, a 180 to $780 \mathrm{~nm}$ of wavelength range, and a $0.02-\mathrm{nm}$ of resolution of the wavelength as a spectral band pass at around $300 \mathrm{~nm}$. As can be seen in Fig. 1, the axial emission from He-MIP was observed as axially viewing He-MIP-OES. The counter Ar gas was blown from the spectrometer window to cool the window wrap the plasma. As a detector of emission, a photomultiplier tube (Hamamatsu R3896) was equipped. The settings were controlled by a computer. In this study, He was chosen as the plasma gas with a flow rate of $11 \mathrm{~L} \mathrm{~min}^{-1}$; the output power was $0.7 \mathrm{~kW}$, and the photomultiplier voltage was $0.8 \mathrm{kV}$.

The plasma discharge tube (outer size $10 \mathrm{~mm}$ in diameter) was a quartz double-pipe concentric structure, and a helix gas flow guide made of quartz was welded between inner and outer tube. $^{25}$ In this study, it was possible to forcibly obtain a higher whirling gas current for $\mathrm{He}$ plasma gas, by providing a helix gas-flow guide in the discharge tube.

For liquid solution samples, we applied an ultrasonic nebulizer (Cetac U6000AT+) with a desolvation and condensation system, with a peristaltic pump (Atto SJ-1211-H). The mist of the solution produced by a transducer of $1.4 \mathrm{MHz}$ was carried by He flow through a heating tube (desolvation, $145^{\circ} \mathrm{C}$ ) and condenser $\left(5^{\circ} \mathrm{C}\right)$, which were used for droplet desolvation and vapor condensation.

Table 1 Chemical composition of slag specimens (mass \%)

\begin{tabular}{lcccccl}
\hline & $\mathrm{CaO}$ & $\mathrm{SiO}_{2}$ & $\mathrm{Al}_{2} \mathrm{O}_{3}$ & $\mathrm{MgO}$ & $\mathrm{Fe}_{2} \mathrm{O}_{3}$ & \multicolumn{1}{c}{$\mathrm{F}$} \\
\hline Slag A & 49 & 24 & 4.8 & 11 & 5.2 & 3.2 \\
Slag B & 38 & 32 & 2.6 & 19 & 2.3 & 0.025 \\
\hline
\end{tabular}

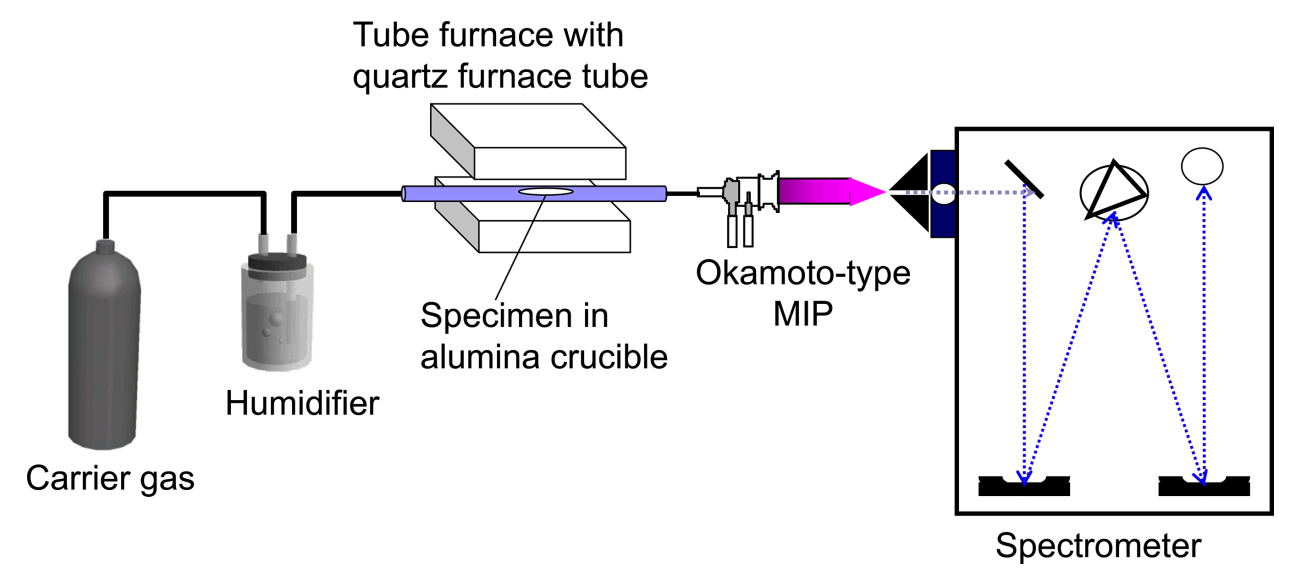

Fig. 1 Instrumental setup of thermal hydrolysis He-MIP-OES. 



FI $703.747 \mathrm{~nm}$

Fig. 2 Calibration curves of F observed at wavelengths of (a) 685.603 and (b) $703.747 \mathrm{~nm}$.

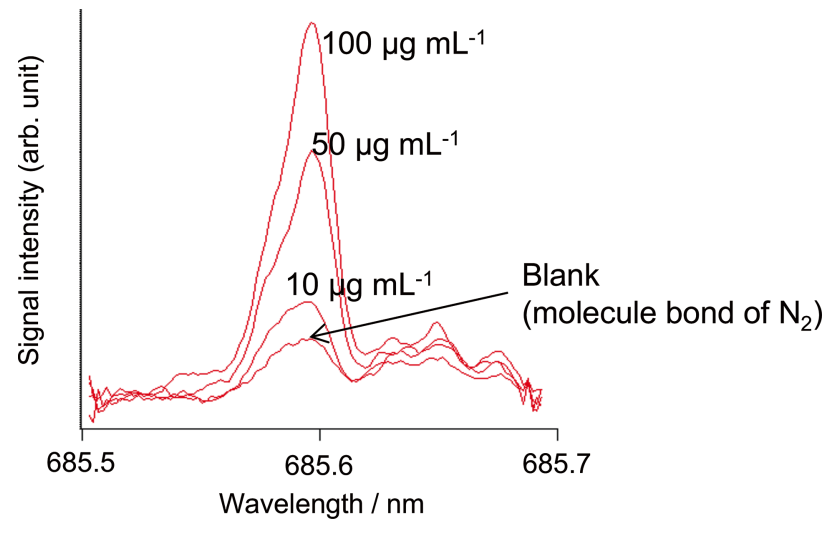

Fig. 3 F spectrum observed at a wavelength of $685.603 \mathrm{~nm}$.

For thermal hydrolysis, a quartz tube-type electric furnace (As One TMF-300N) and humidifier (Horiba Ltd.) were applied. Although the heating temperature was programmable by the furnace, the temperature was monitored by a thermocouple thermometer set at the center of an alumina crucible so as to avoid any overshoot of the temperature. The flow rate of the $\mathrm{He}$ carrier gas was $1.2 \mathrm{~L} \mathrm{~min}^{-1}$, which was then humidified by water at $25^{\circ} \mathrm{C}$. The compounds and specimens in the crucible were heated by a tube furnace from $100^{\circ} \mathrm{C}$ to 1000 or $1200^{\circ} \mathrm{C}$ at a rate of $20^{\circ} \mathrm{C} \mathrm{min}{ }^{-1}$; then, the carrier gas with decomposed elements was introduced into the discharge tube of MIP directly.

\section{Results and Discussion}

Basic quantitative ability of $F$ by He-MIP-OES

The basic quantitative ability of $\mathrm{F}$ by He-MIP-OES with an ultrasonic nebulizer was examined, prior to analyzing gaseous $\mathrm{F}$ extracted from slags. Because to calibrate $\mathrm{F}$ in the gaseous phase was difficult, we applied the conventional solution sample introduction system with ultrasonic nebulizer. Nebulizer gas provided to the ultrasonic nebulizer was $\mathrm{He}$ at a flow rate of $1.2 \mathrm{~L} \mathrm{~min}^{-1}$. Figure 2 shows the calibration curves of $\mathrm{F}$ obtained from a $\mathrm{NaF}$ solution. Two wavelengths of 685.603 and $703.747 \mathrm{~nm}$ were examined, and good linearity could be obtained for both wavelengths. However, a small background peak was observed at $685.603 \mathrm{~nm}$, as shown in Fig. 3, which might be due to the emission from $\mathrm{N}_{2}$ molecules.

The energy state of the $\mathrm{F}$ transition ${ }^{28-31}$ was investigated and estimated. Regarding F (I) $685.603 \mathrm{~nm}$, the transition of the excitation level was $3 \mathrm{p}^{4} \mathrm{D}^{\mathrm{o}} 7 / 2 \rightarrow 3 \mathrm{~s}^{4} \mathrm{P}_{5 / 2}$, and the energy difference could be $14.524 \mathrm{eV}$. Regarding F (I) $703.747 \mathrm{~nm}$, the excitation level transition was $3 \mathrm{p}^{2} \mathrm{P}_{3 / 2} \rightarrow 3 \mathrm{~s}^{2} \mathrm{P}_{3 / 2}$, and the energy difference could be calculated as being $14.752 \mathrm{eV}$. Moreover, the transition probabilities were $4.5 \times 10^{7}$ for $685.603 \mathrm{~nm}$ and $3.8 \times 10^{7}$ for $703.747 \mathrm{~nm}^{32}$. The sensitivity of $685.603 \mathrm{~nm}$ would be higher than that of $703.747 \mathrm{~nm}$, and practically the signal intensity of $685.603 \mathrm{~nm}$ was about 3-times higher than that of $703.747 \mathrm{~nm}$, as shown in in Fig. 2. However, a small background peak of $F$ (I) $685.603 \mathrm{~nm}$ was observed, as shown in Fig. 3. In Fig. 2, there was a small blank in the calibration curve of $F$ (I) $703.747 \mathrm{~nm}$, and the possibility of $\mathrm{F}$ contamination in a blank solution was eliminated. However, the emission of the $\mathrm{N}_{2}$ molecular band $686.0 \mathrm{~nm}^{33}$ interfered with the $\mathrm{F}$ emission $685.603 \mathrm{~nm}$ and which caused a higher blank than F (I) $703.747 \mathrm{~nm}$.

Thus, we adopted $703.747 \mathrm{~nm}$ emission as an analytical line for $\mathrm{F}$ emission monitoring. The limit of quantification (LOQ) of the $703.747 \mathrm{~nm} \mathrm{~F}$ (I) emission line was calculated to be $2.3 \mu \mathrm{g} \mathrm{mL}^{-1}$ by the background equivalent concentration of the calibration curve. Even though a gaseous sample generated by thermal hydrolysis of a slag specimen and that of the liquid solution via an ultrasonic nebulizer would be different under the conditions of a sample introduced into the plasma (sample temperature, water content for example), the quantitative ability of fluorine by He-MIP-OES was confirmed to a certain extent.

\section{$F$ emission from $F$ compounds by thermal hydrolysis He-MIP- OES}

The fluorine extraction profiles from the $\mathrm{F}$ compounds were examined by thermal hydrolysis He-MIP-OES, as shown in Fig. 1. After $20 \mathrm{mg}$ of each $\mathrm{F}$ compound was weighed and taken into a small alumina crucible, it was then inserted into a quartz furnace tube under a $\mathrm{He}$ atmosphere. The carrier gas and decomposed gaseous elements were introduced into the He-MIP directly. As described in the previous section, The $703.747 \mathrm{~nm}$ F (I) emission line was observed continuously by a spectrometer. Figure 4 shows the result of $\mathrm{F}$ (I) emission from each compound; horizontal axis is the heating temperature, and the vertical axis is the $\mathrm{F}$ signal intensity. The heating temperature changed at $20^{\circ} \mathrm{C} \mathrm{min}^{-1}$ up to $1000^{\circ} \mathrm{C}$. It can be seen from Fig. 4 that the behavior of the thermal hydrolysis was different for each $\mathrm{F}$ compound. The peak top of fluorite was about $880^{\circ} \mathrm{C}$; cuspidine 


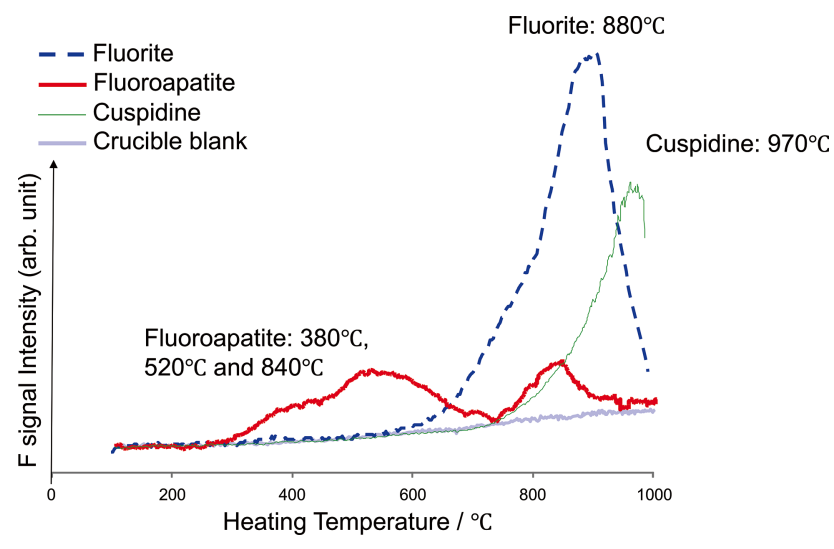

Fig. $4 \quad \mathrm{~F}$ extraction profiles of $\mathrm{F}$ compounds.

Table 2 Concentration of fluorine and estimated $\mathrm{F}$ compounds in slag specimens (mass \%)

\begin{tabular}{ccccc}
\hline & \multirow{3}{*}{ Total F } & \multicolumn{3}{c}{ F compound } \\
\cline { 3 - 5 } & & Fluorire & Cuspidine & Fluoroapatite \\
\hline Slag A & 0.32 & 0.66 & - & - \\
Slag B & 0.025 & 0.01 & 0.12 & 0.23 \\
\hline
\end{tabular}

showed a higher temperature than fluorite. Fluoroapatite has multiple peaks, 380,520 and $840^{\circ} \mathrm{C}$.

We considered the reasons for the multiple peaks of fluoroapatite. F emission of low temperature could be due to the dehydration of crystallization water of fluoroapatite; the middle temperature of $520^{\circ} \mathrm{C}$ could be due to a collapse of the fluoroapatite crystalline structure. As for the high-temperature peak, we thought this was caused by fluorite, which could be contaminated in synthesizing fluoroapatite and/or generated from thermally decomposed fluoroapatite.

Analysis of slag specimens by thermal hydrolysis He-MIP-OES

The thermal hydrolysis He-MIP-OES was carried out to identify any unknown F compound contained in slag specimens. The $100 \mathrm{mg}$ of slags shown in Table 1 grounded to fine particles $(<75 \mu \mathrm{m})$ was heated by the same method for examining compounds. The extraction profile of slag A was obtained as shown in Fig. 5. The solid line is the extraction profile of slag A, which was agreed well with the fluorite profile, as indicated by the broken line. Since the concentration of $\mathrm{F}$ in this slag A was $3.2 \%$ in mass fraction and all $\mathrm{F}$ existed in slag formed fluorite, the concentration of fluorite in this slag was calculated to be $6.6 \%$ in mass fraction. The extraction profile of slag B is shown in Fig. 6, the peaks are assumed to be fluoroapatite at around 380 and $520^{\circ} \mathrm{C}$; fluorite at around $870^{\circ} \mathrm{C}$; and cuspidine at around $1000^{\circ} \mathrm{C}$, were detected, respectively. A small peak at around $200^{\circ} \mathrm{C}$ was unidentified, and was estimated $\mathrm{F}$ contained in dehydrated water from hydrates in slag. Peak fittings were performed and the area ratio of all of $\mathrm{F}$ peaks were calculated as follows, fluoroapatite was 0.33 ; fluorite was 0.19 ; and caspidine was 0.48 . With respect to the chemical structural formula of each mineral and based on the fluorine content in the analytical sample shown in Table 1, it was calculated that $0.01 \%$ of fluorite, $0.12 \%$ of caspidine and $0.23 \%$ of fluoroapatite in mass fraction were contained in slag $\mathrm{B}$. The $\mathrm{F}$ concentration and

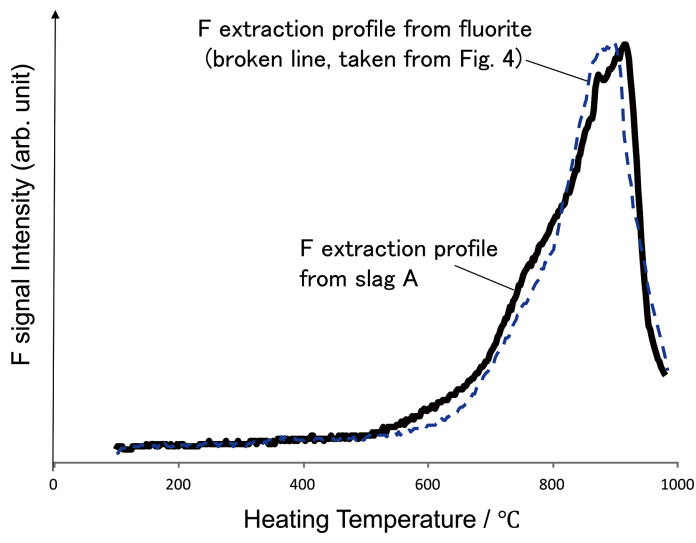

Fig. 5 F extraction profile of slag A.



Fig. 6 F extraction profile of slag B.

calculated concentration of $\mathrm{F}$ compounds are summarized in Table 2. Although there was a possibility that a part of fluorite was the reaction product of decomposed fluoroapatite, it was suggested that the chemical state of $F$ in actual slags could be specified by the thermal hydrolysis He-MIP-OES system developed in this study.

In order to improve the resolution of the thermal hydrolysis profile, a large soaking area of the furnace and a small volume of furnace tube should be necessary. Moreover, there remains the possibility that $\mathrm{F}$ compounds decomposed to some other form of $\mathrm{F}$ compounds by thermal hydrolysis and/or other chemical reaction in slag. The hydration/dehydration of slag components with an endothermic/exothermic reaction could affect to the decomposition of $\mathrm{F}$ compounds. Hence, an analytical validation should be carried out by some other analytical method, such as TG/DTA and solid-state NMR, for example. $\mathrm{F}$ in slag could exist in fluorite, cuspidine and fluoroapatite, as well as in slag matrix of $2 \mathrm{CaO} \cdot 2 \mathrm{SiO}_{2}$, $2 \mathrm{CaO} \cdot 2 \mathrm{SiO}_{2}$, and/or amorphous phase, as some dissolved impurity and/or complex compounds. To elucidate the concentrations and elution behaviors of those compounds, and to take measures to control the slag compounds to prevent $\mathrm{F}$ elution, are necessary. 


\section{Conclusions}

The newly established He-MIP-OES was expected to be useful to quantify $\mathrm{F}$ in solution. Its LOQ was found to be $2.3 \mu \mathrm{g} \mathrm{mL}^{-1}$ by analyzing the F (I) emission line at a wavelength of $703.747 \mathrm{~nm}$. The analytical system of thermal hydrolysis HeMIP-OES developed in this study could measure $F$ in decomposed gas continuously, and thermal hydrolysis temperatures of $\mathrm{F}$ compounds could also be evaluated at such as $880^{\circ} \mathrm{C}$ for fluorite, 380,520 and $840^{\circ} \mathrm{C}$ for fluoroatatite and $970^{\circ} \mathrm{C}$ for cuspidine. The possibility to analyze slag specimens was examined and demonstrated. This study is the first step for the practical use of He-MIP-OES in industry and environmental sciences.

\section{Acknowledgements}

The authors sincerly thank to Prof. Dr. Kazuaki Wagatsuma, Tohoku University, Japan and Prof. Dr. Koichi Chiba, Kwansei Gakuin University, Japan for their useful advices. They would also like to thank to Mr. Toyoharu Okumoto, Dr. Yasushi Terui, Mr. Naoyuki Terunuma, Mr. Nobuyuki Nagai, Mr. Koji Tachibana, Mr. Ryohei Ajima and everyone in Hitachi HighTechnologies group, Japan for their great efforts to establish the He-MIP-OES analytical system. Authors greatly appriciate Dr. Takafumi Takahashi, Nippon Steel \& Sumitomo Metal Corp., Japan for his good work and advices about F compounds.

\section{References}

1. H. Mizukami, M. Ishikawa, T. Hirata, T. Kamiyama, and K. Ichikawa, ISIJ Int., 2004, 44, 623.

2. H. Mizukami, M. Ishikawa, T. Hirata, T. Kamiyama, and K. Ichikawa, ISIJ Int., 2004, 44, 630.

3. T. Miki, K. Shitogiden, Y. Samada, and M. Hino, ISIJ Int. 2004, 44, 935.

4. N. Menad, J. N. Ayala, F. Garcia-Carcedo, E. Ruiz-Ayúcar, and A. Hernández, Waste Management, 2003, 23, 483

5. M. Hayashi, N. Nabeshima, H. Fukuyama, and K. Nagata, ISIJ Int., 2002, 42, 352.

6. H. Kim and I. Sohn, ISIJ Int., 2011, 51, 1.

7. A. Pedone, T. Charpentier, and M. C. Menziania, J. Mater. Chem., 2012, 22, 12599.

8. A. F. Holleman and E. Wiberg, "Inorganic Chemistry", 2001, Academic Press, San Diego, CA.

9. R. Mazelsky, R. H. Hopkins, and W. E. Kramer, J. Cryst.
Growth, 1968, 3-4, 260.

10. T. Watanabe, H. Fukuyama, K. Nagata, and M. Susa, Metall. Mat. Trans. B, 2000, 31, 1273.

11. K.Yanagihara and Y. Giga, Denki-Seiko (in Japanese), 2007, 78,5 .

12. Y. Okamoto, Jpn. J. Appl. Phys., 1999, 38, L338.

13. Y. Okamoto, H. Murohashi, and S. Wake, Anal. Sci., 2000, 17(Supplement), i967.

14. T. Okamoto and Y. Okamoto, IEEJ Trans. FM, 2007, 127, 272.

15. T. Okamoto and Y. Okamoto, IEEJ Trans. FM, 2012, 132, 580.

16. Y. Okamoto, Anal. Sci., 1991, 7, 283.

17. Y. Okamoto and H. Musa, Proceedings of ESCAMPIG 16th ICRP, 2002, Grenoble, France, 355.

18. Y. Okamoto, J. Anal. At. Spectrom., 1994, 9, 745.

19. K. Oishi, T. Okumoto, T. Iino, M. Koga, T. Shirasaki, and N. Furuta, Spectrochim. Acta, Part B, 1994, 49, 901.

20. K. Ogura, H. Yamada, Y. Sato, and Y. Okamoto, Appl. Spectrosc., 1997, 51, 1496.

21. M. Ohata and N. Furuta, J. Anal. At. Spectrom., 1997, 12, 341.

22. T. Nakahara and Y. Li, J. Anal. At. Spectrom., 1998, 13, 401.

23. M. Ohata, H. Ota, M. Fushimi, and N. Furuta, Spectrochim. Acta, Part B, 2000, 55, 1551 .

24. K. Wagatsuma, Appl. Spectrosc. Rev., 2005, 40, 229.

25. T. Okamoto and Y. Okamoto, Bunseki Kagaku, 2009, 58, 545.

26. T. Okamoto, J. Aoyama, J. Ukon, H. Daidoji, M. Aimoto, and Y. Okamoto, Bunseki Kagaku, 2013, 62, 339.

27. L. A. Iacone, W. R. L. Masamba, S.-H. Nam, H. Zhang, M. G. Minnich, A. Okino, and A. Montaser, J. Anal. At. Spectrom., 2000, 15, 491.

28. A. J. Yencha, "Electron Spectroscopy: Theory, Technique, and Applications", ed. C. R. Brundle and A. D. Baker, 1984, Vol. 5, Academic, New York, 198.

29. M. Tsuji, M. Furusawa, T. Mizuguchi, T. Muraoka, and Y. Nishimura, J. Chem. Phys., 1992, 97, 245.

30. M. T. Jones, T. D. Dreiling, D. W. Setser, and R. N. McDonald, J. Phys. Chem., 1985, 89, 4501.

31. O. Leisin, H. Morgner, and H. Seiberle, Mol. Phys., 1985, 56, 349 .

32. W. L. Wiese, M. W. Smith, and B. M. Glennon, "Atomic Transition Probabilities", 1966, Vol. I, Nat. Stand. Ref. Data Ser., NSRDS-NBS 4, U.S. Government Printing Office, Washington, D.C., 153.

33. A. Lofthus and P. H. Krupenie, J. Phys. Chem. Ref. Data, 1977, 6, 113. 